\title{
Allergic airway inflammation induces the migration of dendritic cells into airway sensory ganglia
}

Duc Dung Le', Sabine Rochlitzer ${ }^{2}$, Axel Fischer ${ }^{3}$, Sebastian Heck', Thomas Tschernig ${ }^{4}$, Martina Sester ${ }^{5}$, Robert Bals ${ }^{6}$, Tobias Welte ${ }^{7}$ Armin Braun ${ }^{2}$ and Quoc Thai Dinh ${ }^{1,6^{*}}$

\begin{abstract}
Background: A neuroimmune crosstalk between dendritic cells (DCs) and airway nerves in the lung has recently been reported. However, the presence of DCs in airway sensory ganglia under normal and allergic conditions has not been explored so far. Therefore, this study aims to investigate the localisation, distribution and proliferation of DCs in airway sensory ganglia under allergic airway inflammation.

Methods: Using the house dust mite (HDM) model for allergic airway inflammation BALB/C mice were exposed to HDM extract intranasally $(25 \mu \mathrm{g} / 50 \mu \mathrm{l})$ for 5 consecutive days a week over 7 weeks. With the help of the immunohistochemistry, vagal jugular-nodose ganglia complex (JNC) sections were analysed regarding their expression of DC-markers (MHC II, CD11C, CD103), the neuronal marker PGP 9.5 and the neuropeptide calcitonin gene-related peptide (CGRP) and glutamine synthetase (GS) as a marker for satellite glia cells (SGCs). To address the original source of DCs in sensory ganglia, a proliferation experiment was also carried in this study.

Results: Immune cells with characteristic DC-phenotype were found to be closely located to SGCs and vagal sensory neurons under physiological conditions. The percentage of DCs in relation to neurons was significantly increased by allergic airway inflammation in comparison to the controls (HDM $51.38 \pm 2.38 \%$ vs. control $28.16 \pm 2.86 \%, p<0.001$ ). The present study also demonstrated that DCs were shown to proliferate in jugular-nodose ganglia, however, the proliferation rate of DCs is not significantly changed in the two treated animal groups (proliferating DCs/ total DCs: HDM $0.89 \pm 0.38 \%$, vs. control $1.19 \pm 0.54 \%, p=0.68$ ). Also, increased number of CGRP-positive neurons was found in JNC after allergic sensitisation and challenge (HDM 31.16 $\pm 5.41 \%$ vs. control $7.16 \pm 1.53 \%, p<0.001$ ).

Conclusion: The present findings suggest that DCs may migrate from outside into the ganglia to interact with sensory neurons enhancing or protecting the allergic airway inflammation. The increase of DCs as well as CGRP-positive neurons in airway ganglia by allergic airway inflammation indicate that intraganglionic DCs and neurons expressing CGRP may contribute to the pathogenesis of bronchial asthma. To understand this neuroimmune interaction in allergic airway inflammation further functional experiments should be carried out in future studies.
\end{abstract}

Keywords: House dust mite mouse model, Dendritic cells, Allergic airway inflammation, Sensory airway nerves, Neuroimmune interaction, CGRP

\footnotetext{
*Correspondence: Thai.Dinh@uks.eu

${ }^{1}$ Department of Experimental Pneumology and Allergology, Saarland

University Faculty of Medicine, Kirrberger Strasse, Geb. 61.4, Homburg,

Germany

${ }^{6}$ Department of Internal Medicine V, Pneumology, Allergology and

Respiratory Critical Care Medicine, Saarland University Faculty of Medicine,

Kirrberger Strasse, Geb. 61.4, Homburg, Germany

Full list of author information is available at the end of the article
} 


\section{Introduction}

Allergic bronchial asthma is a chronic inflammatory respiratory disease characterised by airway obstruction, bronchial hyperreactivity and airway inflammation with the recruitment of a variety of immune cells including dendritic cells (DCs) [1-3]. DCs are phagocytic cells that are localised in many organs like in the skin, in the mucosa of the intestines, the upper airways, the lungs and the brain [2-5].

In the allergic sensitisation phase, DCs play a key role as professional antigen presenting cells in the allergic airway inflammation $[3,4,6]$. They capture the antigen, process and subsequently present it on the MHC class II molecules (MHC II) to naïve $\mathrm{T}$ lymphocytes in local lymph nodes leading to cascades of the Th2-immune allergic inflammatory processes $[4,7,8]$. Recently, the maturation and differentiation of DCs have been described to be modulated by many cytokines of immune cells as well as neuropeptides such as calcitonin gene-related peptide (CGRP) [9-11].

CGRP consists of 37 amino acids [12] and is biosynthesised and released from sensory neurons innervating the airways in response to different stimuli including allergic airway inflammation [12-14]. CGRP released from airway nerve fibres has the capacity to act as chemoattractant factor for different immune cells such as $\mathrm{CD}^{+}$T-lymphocytes, CD8 ${ }^{+}$T-lymphocytes, eosinophils and DCs and to induce the proliferation of airway epithelial cells $[9,15-19]$. On the other hand, DCs have the capacity to release neurotrophins, which can activate neurons leading to the production of neuropeptides causing neurogenic airway inflammation [20,21]. Previously, DCs were found to be frequently associated anatomically with CGRP-containing sensory nerve fibres of the airways and skin $[22,23]$.

Peripheral airway sensory nerve fibres are known to be derived from the neuronal cell bodies which are located in jugular-nodose ganglia complex (JNC) and able to produce, store and release neuropeptides such as tachykinins and CGRP to cause neurogenic inflammation [24-26]. However, DCs in airway sensory ganglia have not been explored under normal and allergic airway conditions so far.

The present study, therefore, aimed to investigate the localisation, distribution and proliferation of DCs and CGRP immunoreactive (IR)-neurons in vagal sensory jugular-nodose ganglia under allergic airway inflammation by using a chronic house dust mite (HDM) mouse model.

\section{Materials and methods \\ Animals}

Female wild-type BALB/c-mice (6-8 weeks old) were purchased from Charles River. The animals were held in regular $12 \mathrm{~h}$ dark/light cycles at a temperature of $22^{\circ} \mathrm{C}$ and received laboratory food and tap water ad libitum. The animals were acclimatised for at least 2 weeks prior to the study. All animal experiments were performed in strict concordance with the German animal protection law and approved by the appropriate governmental authority (No. 10/0207 and 14/2013).

\section{HDM-mouse model}

To induce chronic allergic airway inflammation, BALB/c mice $(n=10)$ were exposed consecutively 5 days a week within a total period of 7 weeks by intranasal instillation of HDM extract (Greer Inc., Cat. No XPB82D3A2.5) with a dose of $25 \mu \mathrm{g}$ protein in $50 \mu \mathrm{l}$ saline. A second group of animals $(n=10)$ served as control and was treated intranasal with $50 \mu \mathrm{l}$ saline. Analyses were performed $24 \mathrm{~h}$ after the last allergen challenge (Figure 1) $[27,28]$.

\section{In vivo proliferation study with EdU (5-ethynyl-2'-deoxyuridine)}

EdU is a nucleoside analog of thymidine and is incorporated into DNA during active DNA synthesis. Controls and HDM-treated animals received an i.p. injection of $1 \mathrm{mg}$ EdU (Invitrogen) in a volume of $200 \mu \mathrm{l} 24 \mathrm{~h}$ before sacrifice.

\section{Bronchoalveolar lavage fluid (BALF)}

Bronchoalveolar lavage was performed by instillation of $0.8 \mathrm{ml}$ ice-cold PBS twice as described before [10]. The BALF was centrifuged $\left(320 \times \mathrm{g}, 10 \mathrm{~min}, 4^{\circ} \mathrm{C}\right)$ and the supernatants were removed. The cell pellets were resuspended in $0.5 \mathrm{ml}$ PBS and counted automatically with a Casy $^{\circ}$ cell counter. Cytospots were prepared, stained according to Pappenheim and differential cell counts were evaluated.

\section{Lung histology}

For the assessment of the airway inflammation, acetone fixed lung cryosections of allergen sensitised/challenged and control animals were stained with hematoxylin and eosin. Cryosections $(10 \mu \mathrm{m})$ were prepared using a cryostat (CM1950; Leica Cryostat, Nussloch, Germany) and stained with hematoxylin and eosin (H\&E) and Periodic Acid Schiff (PAS) according to standard protocols.

\section{Ganglion preparation}

JNC ganglia were fixed in Zamboni solution (Morphisto Evolutionsforschung und Anwendung GmbH, Frankfurt am Main, Germany) for six hours, rinsed overnight in $0.1 \mathrm{M}$ phosphate buffered saline (PBS) and cryoprotected $24 \mathrm{~h}$ with $30 \%$ sucrose in $0.1 \mathrm{M}$ PBS. All steps above were performed at $4^{\circ} \mathrm{C}$. The ganglia were embedded in OCT and frozen in liquid nitrogen. Serial $8 \mu \mathrm{m}$ sections of the ganglia were prepared using a cryostat 


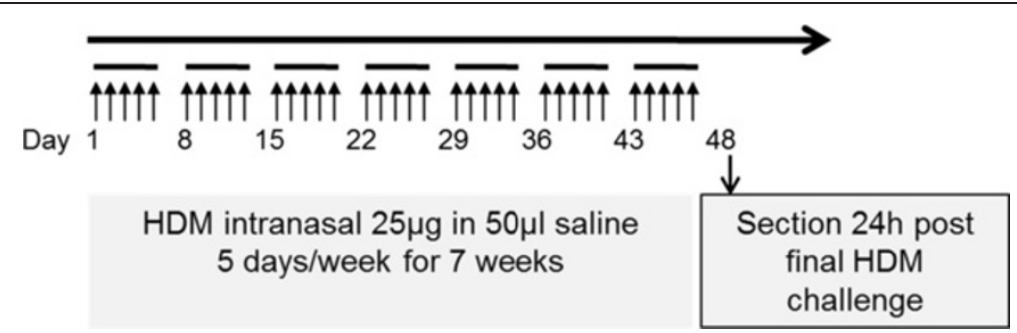

Figure 1 Allergic sensitisation and challenge protocol of chronic HDM mouse model. The animals were systemically sensitised by intranasal application of house dust mite 5 days a week for 7 weeks. All analyses were carried out 24 hours after the final challenge.

(Leica CM 1900, Bensheim, Germany), placed on APES (3-aminopropyltriethoxysilane) coated glass slides, dried at room temperature for $30 \mathrm{~min}$ and then stored in the freezer at $-80^{\circ} \mathrm{C}$.

\section{Immunofluorescence staining}

Every fourth section from serial sections of the JNC was dried at room temperature for $15 \mathrm{~min}$ and then rehydrated for $5 \mathrm{~min}$ in PBS. To reduce nonspecific antibody binding, the sections were incubated for $15 \mathrm{~min}$ at room temperature in $5 \%$ normal serum of the host species of the secondary antibody diluted in PBS. The sections were incubated with primary antibodies against PGP 9.5, MHC II, GS, CD11c, CD103, CD11b, F4/80, Iba1, GFAP, CGRP, or the appropriate isotype control antibodies (listed in Table 1) for $1 \mathrm{~h}$ at room temperature and then overnight at $4^{\circ} \mathrm{C}$. After rinsing with $0.1 \mathrm{M}$ PBS twice, the sections were incubated with secondary fluorescein conjugated antibodies (listed in Table 1) for $2 \mathrm{~h}$ at room temperature, for counterstaining the section then were incubated with $100 \mu \mathrm{l}$ DAPI $(0.5 \mu \mathrm{g} / \mathrm{ml}$, Carl Roth, Germany) for $15 \mathrm{~min}$ at room temperature. Finally the sections were washed twice with 0.1 M PBS, once with double distilled water, mounted with fluorescent mounting medium Prolong Gold (Invitrogen) and covered with cover slips.

Quantitative analysis of MHC II IR-cells, CGRP irneurons and PGP 9.5 ir-neurons was visualised with epifluorescence microscopes (Axioskop 2 plus, Carl Zeiss and Olympus BX5), and cell counting was performed using the software ImageJ (National Institutes of Health). The evaluations of MHC II IR-cells and CGRP IR-neurons were normalised by the total neuron number and expressed as percentages.

Confocal images were acquired by LSM 510 META (Carl Zeiss, Jena, Germany). The Images were processed using Imaris 4.5.2 (Bitplane, Zurich, Switzerland).

\section{EdU staining and quantification of EdU-labelled cells in JNC}

EdU staining was conducted using Click-i ${ }^{\mathrm{TM}}$ Cell Reaction Buffer Kit and Alexa Fluor 594 azide (Invitrogen) according to the manufacture's protocol. The JNC sections were rehydrated for $5 \mathrm{~min}$ in PBS and the blocked with 5\% normal serum. The sections were incubated with $200 \mu \mathrm{l}$ prepared Click-iT reaction cocktail for $30 \mathrm{~min}$ and then incubated with primary and secondary antibodies as described above. Primary antibodies included rat anti-mouse MHC class II (Biolegend) and rabbit anti-mouse PGP 9.5 (Abcam). Secondary detection was performed with donkey anti-rat $\mathrm{Cy} 2$ and donkey anti-rabbit DyLight 647 (Jackson ImmunoResearch) (Table 1). DAPI was used for counterstaining.

For the quantification, 16 sections of each mouse were analysed. Only the EdU-labelled and MHC II- and DAPIpositive cells were observed for quantification of proliferating cells. Evaluations of proliferating, MHC II positive cells with an EdU-labelled nucleus were normalised with the total MHC II positive cells and expressed as percentages.

\section{Statistical analysis}

Data is given as mean \pm SEM. Statistical significance between groups was analysed with unpaired t-test using GraphPad Prism 4.03. Results of P values $<0.05$ were considered significant.

\section{Results}

HDM induces allergic airway inflammation

HDM induced chronic allergic airway inflammation is indicated by the recruitment of eosinophils, neutrophils, lymphocytes and macrophages to the lung (Figure 2A). The histological analysis with $H \& E$ and PAS staining of the lung tissues showed massive infiltration of mononuclear cells (Figure 2B) and a high mucus secretion (Figure 2C) in HDM-sensitised and -challenged mice. In contrast, the lung sections of control mice did not contain inflammatory cell aggregates (Figure 2D) and no mucus secretion was detected (Figure 2E).

\section{DCs are located in JNC and increased during allergic airway inflammation}

JNC sections were analysed by immunofluorescent staining for the expression of pan-neuronal marker PGP 9.5 and MHC II to identify sensory neurons and DCs and assess the 
Table 1 List of antibodies used in this study

\begin{tabular}{|c|c|c|}
\hline Antibody & Source & Dilution \\
\hline \multicolumn{3}{|l|}{ Primary purified antibodies } \\
\hline Rabbit polyclonal antibody against mouse, human PGP 9.5 & Abcam, Cambridge, UK & $1: 200$ \\
\hline Rat monoclonal antibody against mouse I-A/I-E & BioLegend, San Diego, USA & $1: 200$ \\
\hline Goat polyclonal antibody against mouse CGRP & Acris, Herford, Germany & $1: 400$ \\
\hline Armenian hamster monoclonal antibody against mouse CD11c & Abcam, Cambridge, UK & $1: 100$ \\
\hline Armenian hamster monoclonal antibody against mouse CD103 & eBioscience, San Diego, USA & 1:100 \\
\hline Rat monoclonal antibody against mouse CD11b & eBioscience, San Diego, USA & $1: 100$ \\
\hline Rat monoclonal antibody against mouse F4/80 & eBioscience, San Diego, USA & 1:100 \\
\hline Rabbit polyclonal antibody against mouse glutamine synthetase (GS) & Abcam, Cambridge, UK & $1: 500$ \\
\hline Rabbit Rabbit polyclonal antibody against lba1 & Wako Chemicals, Japan & 1:300 \\
\hline Goat polyclonal antibody against GFAP & Abcam, Cambridge, UK & $1: 200$ \\
\hline \multicolumn{3}{|l|}{ Isotype control purified antibodies } \\
\hline Rabbit lgG & Dianova, Hamburg, Germany & 1:5000 \\
\hline Rat lgG 2b kappa & BioLegend, San Diego, USA & $1: 200$ \\
\hline Goat lgG & R\&D systems, & 1:300 \\
\hline Armenian Hamster lgG & BioLegend, San Diego, USA & $1: 200$ \\
\hline \multicolumn{3}{|l|}{ Secondary antibodies } \\
\hline DyLight 488 conjugated Donkey Anti-Rabbit lgG antibody & Jackson ImmunoResearch, INC., Baltimore, USA & $1: 400$ \\
\hline Cy3 conjugated Donkey Anti-Rat lgG antibody & Jackson ImmunoResearch, INC., Baltimore, USA & 1:500 \\
\hline Cy3 conjugated Donkey Anti-Rabbit IgG antibody & Jackson ImmunoResearch, INC., Baltimore, USA & $1: 400$ \\
\hline DyLight 488 conjugated Donkey Anti-Goat lgG antibody & Jackson ImmunoResearch, INC., Baltimore, USA & 1:400 \\
\hline Dylight 649 conjugated Goat Anti-Armenian Hamster lgG antibody & Jackson ImmunoResearch, INC., Baltimore, USA & $1: 400$ \\
\hline DyLight 649 conjugated Donkey Anti-Rabbit lgG antibody & Jackson ImmunoResearch, INC., Baltimore, USA & 1:400 \\
\hline Cy3 Conjugated Donkey Anti-Goat lgG & Jackson ImmunoResearch, INC., Baltimore, USA & $1: 500$ \\
\hline Cy5 conjugated Donkey Anti-Rat lgG antibody & Jackson ImmunoResearch, INC., Baltimore, USA & $1: 400$ \\
\hline
\end{tabular}

anatomical localisation. Within the ganglia, neurons and nerve fibres were strongly immunoreactive for PGP 9.5 indicating that these cells were neurons and nerve fibres. Nerve fibres formed bundles crossing the ganglia. Under physiological and allergic conditions, DCs were observed to be widely distributed over the whole JNC and were located between the neurons and nerve fibres which were immunoreactive for PGP 9.5 (Figure 3).

To determine how the number of DCs in JNC changed during allergic airway inflammation, DCs and neurons in JNC of HDM-treated and control mice were quantified by using $\mathrm{MHC}$ II- and the pan-neuronal marker PGP 9.5- immunoreactivity. The percentage of DCs in relation to the overall neurons was significantly increased in HDM-treated mice (Figure 3C) if compared to the controls (Figure 3D) (DCs/neurons: HDM 51.38 $\pm 2.38 \%(n=9)$ vs. control $28.16 \pm 2.86(n=10), p<0.001$, Figure $3 E)$.

To confirm whether the increase of DCs in JNC is caused by the targeted infiltration or global infiltration, the presence of MHC II-IR cells in trigeminal ganglia, which partly innervate the upper airways, has also been examined by immunohistochemistry. MHC II-IR cells have been found in trigeminal ganglia under physiological condition, and their numbers were not significantly changed by allergic airway inflammation (Figure 3F, G, H).

\section{Phenotypic characterisation of DCs in JNC}

To identify and characterise DCs phenotypically, various surface markers of DCs have been used for this study. In this respect, JNC sections were stained with antibodies against different markers of DCs such as MHC II, CD11c, CD11b, CD103, and Iba1. To discriminate DCs from macrophages, that also express these markers, the ganglia sections were additionally stained with the antibody against F4/80, which is the best known and extensively referenced marker for mouse macrophages. The staining results demonstrated a substantial number of cells in JNC that were strongly immunoreactive for MHC II, CD103 and Iba1. MHC II IR-cells have been found to be totally colocalised with CD103 and Iba1. The staining for CD11b and F4/80 marker did not show any immunoreactivity in MHC II IR-cells. Most 

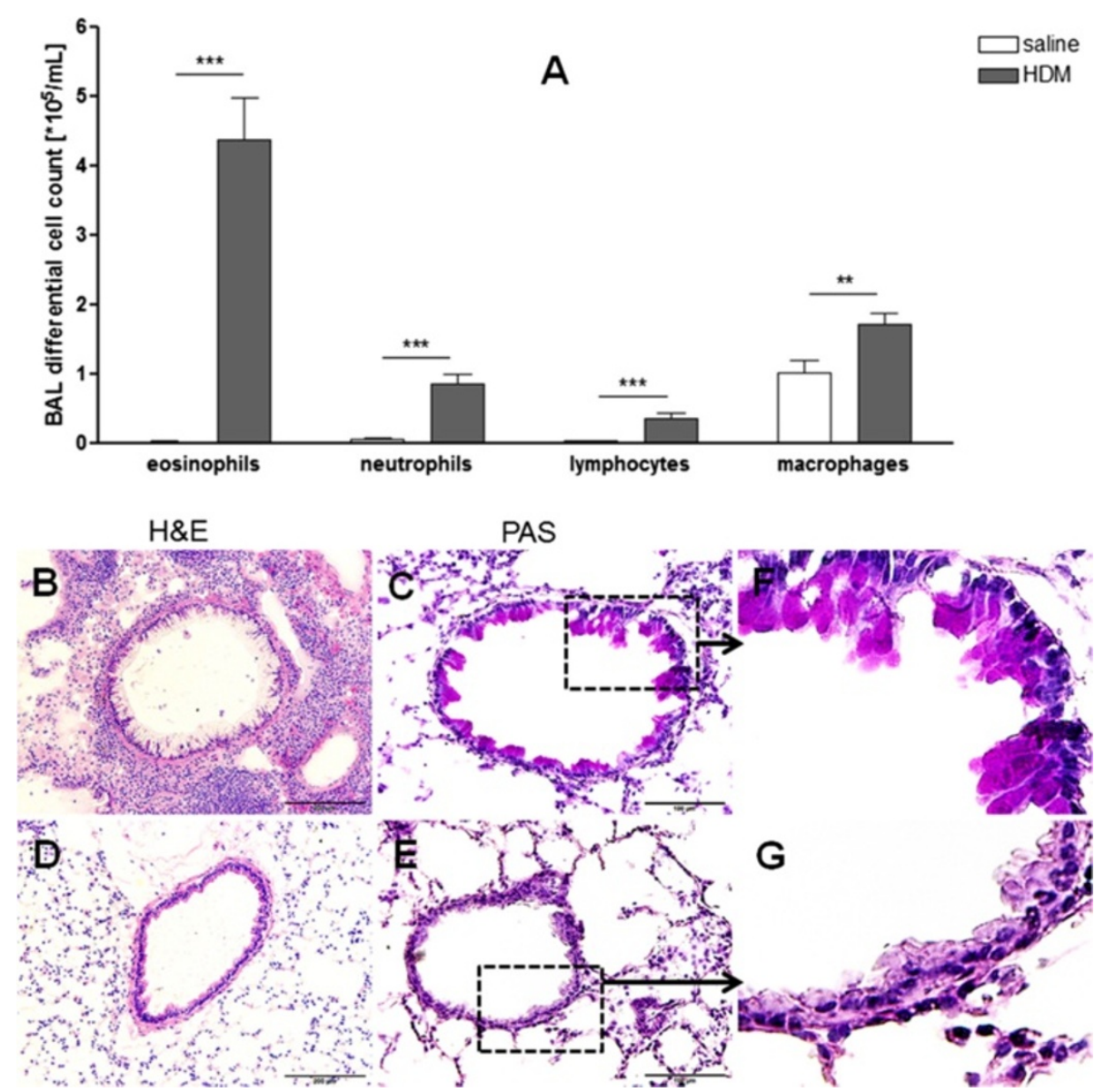

Figure 2 The inflammatory response in the lungs observed after continuous expose to HDM. Bronchoalveolar lavage fluid (BALF) cells differentiation (A). Eosinophils, neutrophils, lymphocytes and macrophages in BALF demonstrated inflammation in the lungs of HDM-exposed mice, in comparison with control mice. Results are expressed as mean $\pm \mathrm{SEM}$. ${ }^{* * P}<0.01$, ${ }^{* *} \mathrm{P}<0.001$ (unpaired two-tailed t-test). Representative photomicrographs of $\mathrm{H} \& \mathrm{E}(\mathrm{B}, \mathrm{D}, \mathrm{G})$ and $\mathrm{PAS}(\mathrm{C}, \mathrm{E}, \mathrm{F})$ stained lung sections. The lung sections from HDM-sensitised and challenged mice showed an infiltration of mononuclear cells (B) and a highly mucus secretion (C) in the airways, whereas the lungs of the control mice do not contain aggregated inflammatory cells (D) and mucus secretion (E). F and $\mathbf{G}$ : larger magnifications of $\mathbf{C}$ and $\mathbf{E}$. Scale bars of $\mathbf{B}$ and $\mathbf{D}$ : $200 \mu \mathrm{m}$, scale bars of $\mathbf{C}$ and $\mathbf{E}: 100 \mu \mathrm{m}$.

of the MHC II-IR cells were immunoreactive for CD11c (CD11c-IR cells/MHC II-IR cells: HDM group: $98.84 \pm 0.70 \%(n=4)$, control group: $97.36 \pm 0.60 \%(n=5))$. These findings demonstrated a subpopulation of DCs in

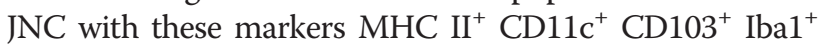
F4/80- $\mathrm{CD} 11 \mathrm{~b}^{-}$(Figure 4).

\section{Discrimination between DCs and glia cells in JNC}

The expression of MHC II molecules has been described not only in conventional antigen-presenting cells (APC) but also in human trigeminal satellite glia cells (SGCs) [29]. Therefore, the discriminations of DCs from SGCs and other glia cells in mouse airway ganglia were determined. JNC sections were stained with the SGC marker glutamine synthetase (GS), astrocyte marker glial fibrillary acidic protein (GFAP) and the APC marker MHC II. The results showed that the GS positive cells were located around neurons and formed an envelope around the sensory neurons. SGCs in JNC were found to be small-sized cells with a thin cytoplasm and a small cell nucleus without APC phenotype. These cells were negative for MHC IIimmunoreactivity indicating that they were not identical with DCs, characterised with MHC II. Furthermore, GS positive cells display a different anatomical structure than the MHC II positive cells identified as DCs in JNC. Further analysis demonstrated that MHC II-IR cells in JNC are negative for GFAP and therefore they do not belong to astrocyte subpopulation of glia cells (Figure 5).

\section{Increase of CGRP-immunoreactive-neurons in JNC in} allergic airway inflammation

Similarly to the finding for DCs, the percentage of CGRP ir-neurons in relation to the JNC-overall neurons was also found to be significantly elevated in HDM-treated 


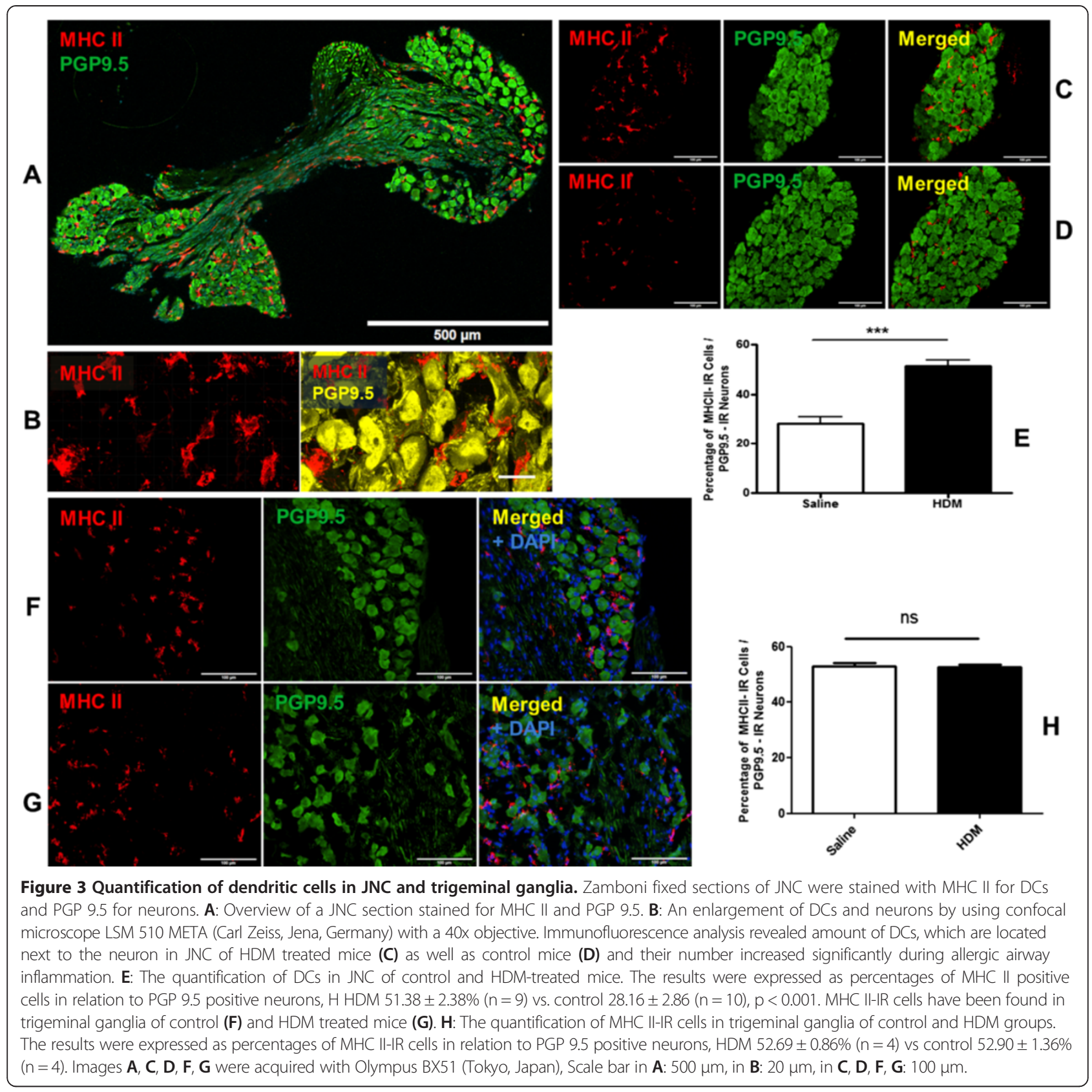

mice (Figure 6A) when compared to the control mice (Figure 6B) (CGRP-positive neurons/total neurons: HDM $31.16 \pm 5.41 \%(n=9)$ vs. control $7.16 \pm 1.53 \%(n=10)$, $\mathrm{p}<0.001$, Figure $6 \mathrm{C}$ ). Additionally, MHC II-positive cells have been found to have an overall distribution on the JNC slices without any preferentially location to CGRP-positive neurons (Figure 6D).

\section{Proliferating DCs in JNC during allergic airway inflammation}

To examine whether DCs proliferated in JNC or migrated from outside into the ganglia during allergic airway inflammation, the animals were injected with EdU, which is incorporated with DNA of dividing cells. Systemic administration of EdU $24 \mathrm{~h}$ before analysis assured the detection of proliferating cells. The proliferating DCs in two groups were evaluated and expressed as percentage of MHC II positive cells with EdU-labelled nucleus/ total MHC II positive cells. The results showed no significant change of proliferating DCs ratio between two groups (proliferating DCs/ total DCs: HDM $0.89 \pm 0.38 \%$, $(n=4)$ vs. control $1.19 \pm 0.54 \%,(n=5), p=0.68$, Figure 7G). Additionally, proliferation of neurons as well as SGCs was not found in the experiments. Further EdU experiments for 

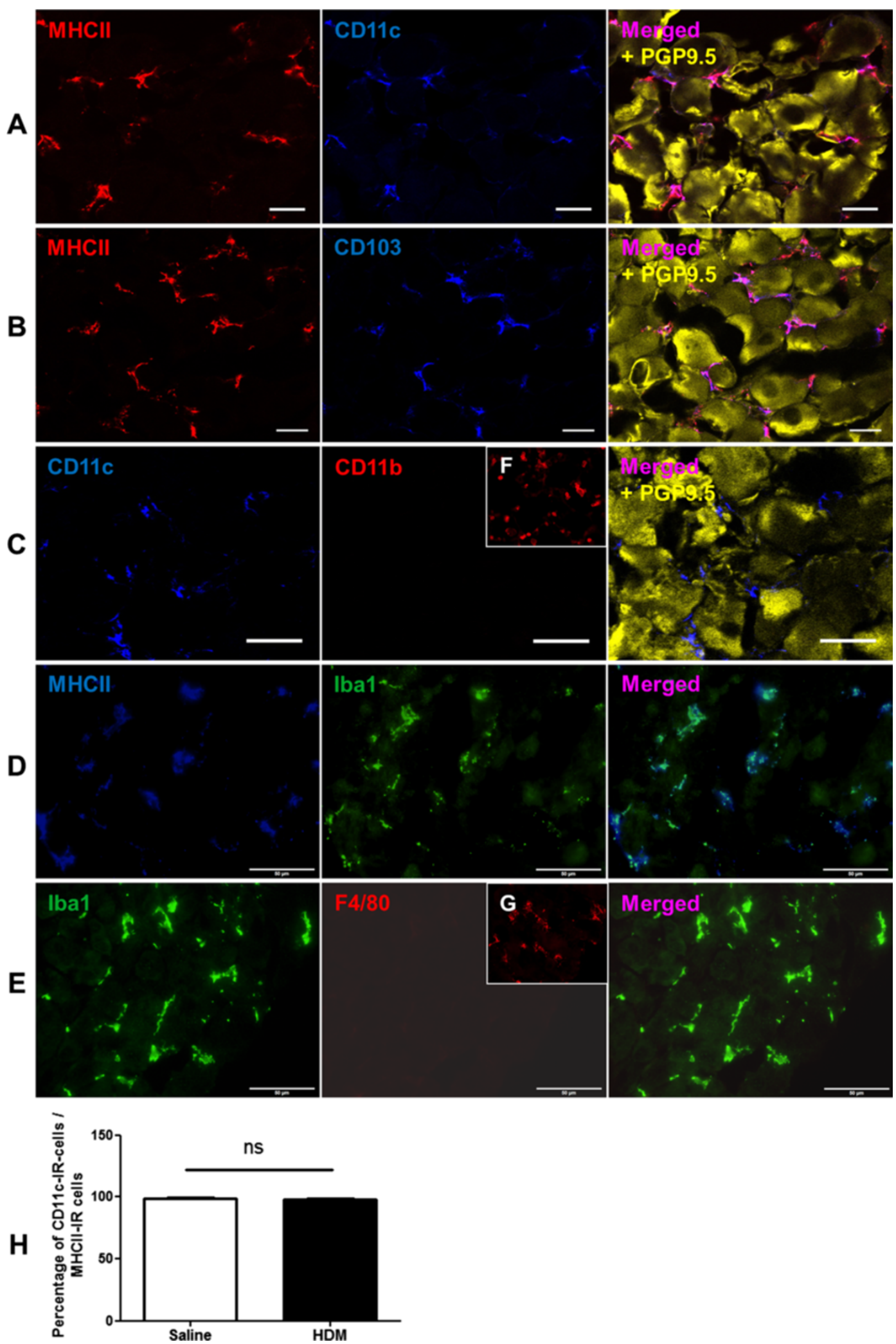

Figure 4 (See legend on next page.) 
(See figure on previous page.)

Figure 4 Phenotypic characterisation of DCs in JNC. JNC sections were stained for different cell markers and images were acquired with confocal microscope LSM 510 META (Carl Zeiss, Jena, Germany) using a 40x objective and Olympus BX51 (Tokyo, Japan) using a 20x, 40x objectives. The Immunofluorescence analysis showed the immune cells in JNC positive for MHC II and CD11C (A), positive for MHC II and CD103 (B), positive for CD11C and negative for CD11b (C), positive for MHC II and Iba1 (D), positive for Iba1 and negative for F4/80 (E). F: Positive control of CD11b antibody in the lung tissue. G: Positive control of CD11c antibody in trigeminal ganglion. Yellow cells in $\mathbf{A}$, $\mathbf{B}$, $\mathbf{C}$ are neurons, which are stained with antibody against PGP 9.5. $\mathbf{H}$ : The quantification of CD11C-IR cells in JNC, the results were expressed as percentages of CD11c-IR cells in relation to MHC II-IR cells. Scale bars represent in A, B, C: $20 \mu \mathrm{m}$, in D, E: $50 \mu \mathrm{m}$.

the positive controls have been carried out in lung tissue of HDM treated mice. The finding showed a large population of MHC II-IR cells of the lung also strongly positive for EdU, showing the DCs proliferation in the lung (Figure $7 \mathrm{H}$ ).

\section{Discussion}

Dendritic cells play a pivotal role as antigen sampling and presenting cells in the initiation and development of allergic response such as allergic airway inflammation $[3,4,8]$. Previous studies have revealed that DCs were found to be localised in the neighbourhood of peripheral CGRP-positive nerve fibres in the airways [22]. The role of this DC-nerve interaction in allergic airway inflammation, however, has not been clear yet.

CGRP has been discussed to have the capacity to modulate DCs during the allergic airway inflammation. CGRP is known to be produced by the cell bodies located in JNC, anterogradely transported and released by the peripheral nerve fibres innervating the airways [12-14]. In this respect, the present study aimed to investigate the localisation, distribution and proliferation of DCs in JNC by using HDM mouse model for allergic airway inflammation.
After continuous intranasal administration with HDM extract, a chronic airway inflammation was induced as previously reported [27]. In accordance to other studies, inhalation of HDM extract led to a significant increase of the recruitment of eosinophils as well as a substantial number of neutrophils, macrophages and lymphocytes $[27,28]$. With the characteristic of mixed eosinophilic and neutrophilic inflammation, the HDM mouse model becomes an interesting animal model that may closely reflect the situation of severe bronchial asthma in human [1].

Interestingly, for the first time, cells expressing MHC II molecules were identified in JNC of mice under physiological conditions. The immunofluorescence analysis revealed that these cells belong to the immune cell population rather than to the nervous system as they were non-reactive for the pan-neuronal marker PGP 9.5. Additionally, these immune cells exhibited DC phenotypes as they displayed high immunoreactivity for MHC II and CD103 while negative for CD11b- and F4/80-immunoreactivity. Most (about 98\%) of MHC II-IR cells were immunoreactive for CD11c indicating these cells are DCs. MHC II-IR cells have also been found to be totally colocalised with Iba1, which has been reported to be expressed in
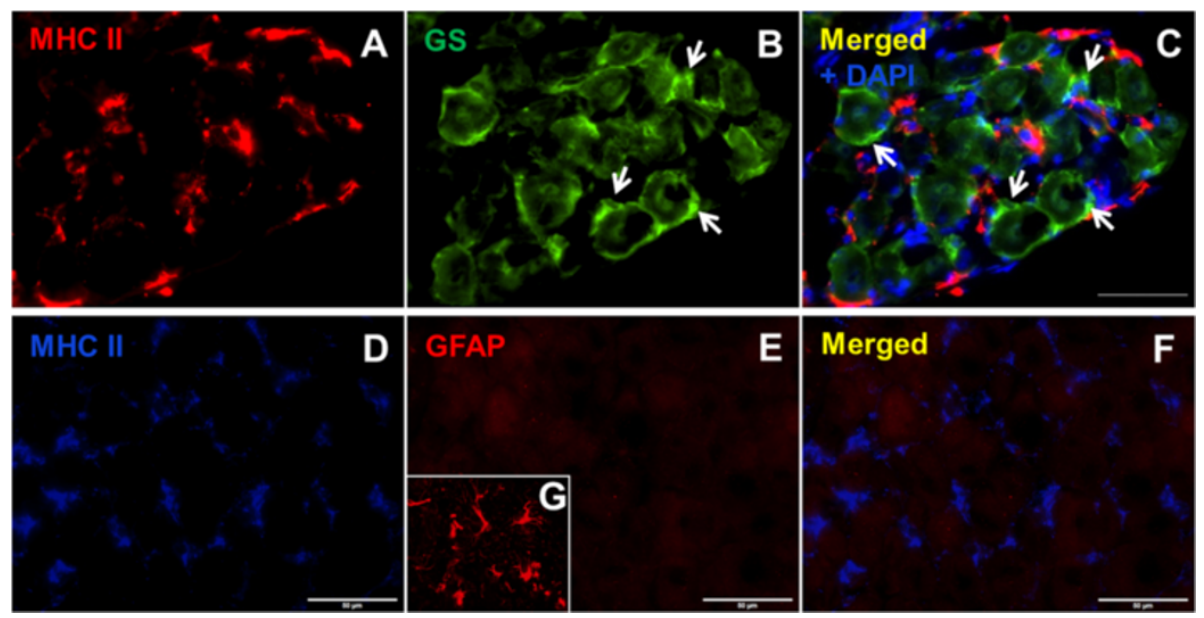

Figure 5 Distinction between DCs and glia cells in JNC. A: DCs are immunoreactive with MHC II. B: Satellite glia cells (SGCs, arrows) are immunoreactive for glutamine synthetase (GS). C: MHC II-IR cells have no overlaps with SGCs immunoreactive for GS, the separate cell nucleus of SGCs and DCs are stained with DAPI. The dendritic cells with immunoreactivity for MHC II (D) were also stained with astrocyte marker GFAP, these dendritic cells expressed no GFAP (E). F: merged representation of MHC II and GFAP. G: positive control of GFAP antibody in mouse brain section. scale bars: $50 \mu \mathrm{m}$. 


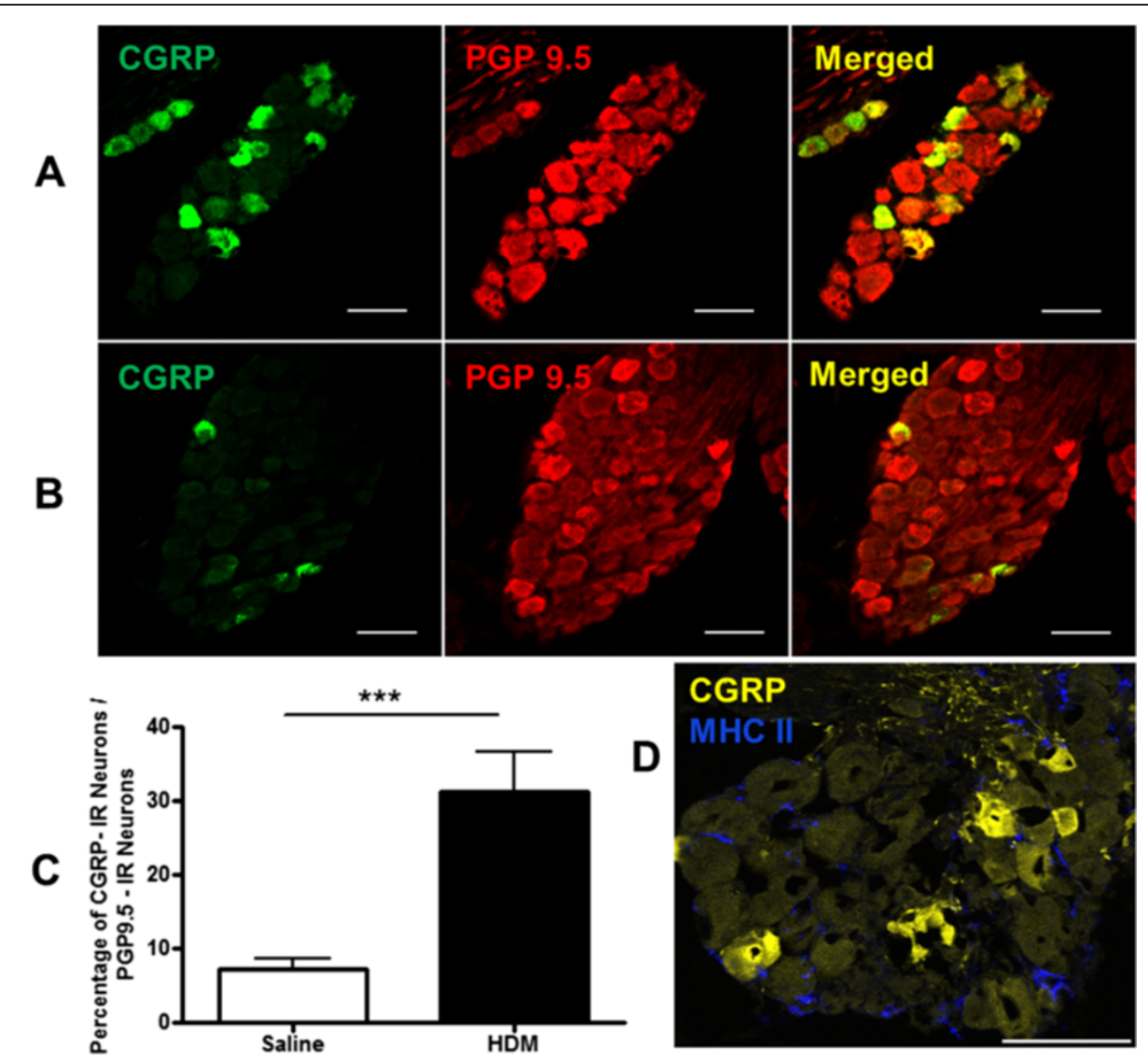

Figure 6 Increased numbers of CGRP-positive neurons under allergic condition. The JNC sections of HDM treated animals and control animals were stained with antibodies against neuropeptides CGRP and PGP 9.5. The amount of CGRP positive neurons increased significantly during allergic airway inflammation (A) in comparison to that of the controls (B). Scale bars: $50 \mu \mathrm{m}$. Images were acquired with Axioskop 2 plus (Zeiss) using a 40x objective. C: The quantification of CGRP ir-neurons in JNC of control and HDM-treated mice. The results were expressed as percentage of CGRP-IR-neurons in relation to all PGP 9.5 positive neurons, HDM 31.16 $\pm 5.41 \%(n=9)$ vs. control 7.16 $\pm 1.53 \%(n=10), p<0.001$. D: MHC II-positive cells distribute overall on the JNC slices without any preferentially location to CGRP-positive neurons. Image was acquired with confocal microscope LSM 510 META (Carl Zeiss, Jena, Germany), scale bar: $50 \mu \mathrm{m}$.

DCs in the brain and other organs such as intestine and skin [5,30,31]. A very small population with MHC II-IR did not express CD11c $(<2 \%)$. These cell types are still unknown and remain to be investigated in future study.

The localisation of DCs within the sensory ganglia was found to be widely distributed on the whole ganglia and between SGCs and/or neurons. Recently, other neuronal cells, such as SGCs in human trigeminal ganglion, have also been shown to express MHC II [29]. However, the present findings revealed that SGCs in mouse JNC to be negative for MHC II. The contrary findings of the SGC population may be caused by the ganglionic- and species-specific differences between mouse and human $[29,32]$. The exact role of SGCs in JNC under physiological and allergic situations remains to be investigated in future experiments.

For the discrimination of DC migration into the ganglia as a targeted infiltration and systemic infiltration, further studies have been carried out in trigeminal ganglia. In contrast to the JNC, where the numbers of DCs were significantly increased during allergic airway inflammation, the numbers of MHC II-IR cells in trigeminal ganglia, however, were not changed. These contrary findings may be caused by the ganglionic- or organ-specific differences between JNC and trigeminal ganglia. Anatomically, trigeminal ganglia are located inside the cranium, whereas JNC are found to be under the skullbase. Additionally, the two ganglia have different embryonic development.

The findings of the increase of DCs in the JNC lead to further questions of their origin. The results of the proliferation study suggest that DCs may move from the systemic blood circulation into JNC by passing through the ganglion-blood barrier. In contrast to the brainblood barrier, the ganglion-blood barrier is known to be only discontinuously formed [33]. Alternatively, DCs may reach the JNC along the vagus from the peripheral airways by retrograde migration when their numbers in the airways and the blood system were to be enhanced during allergic 


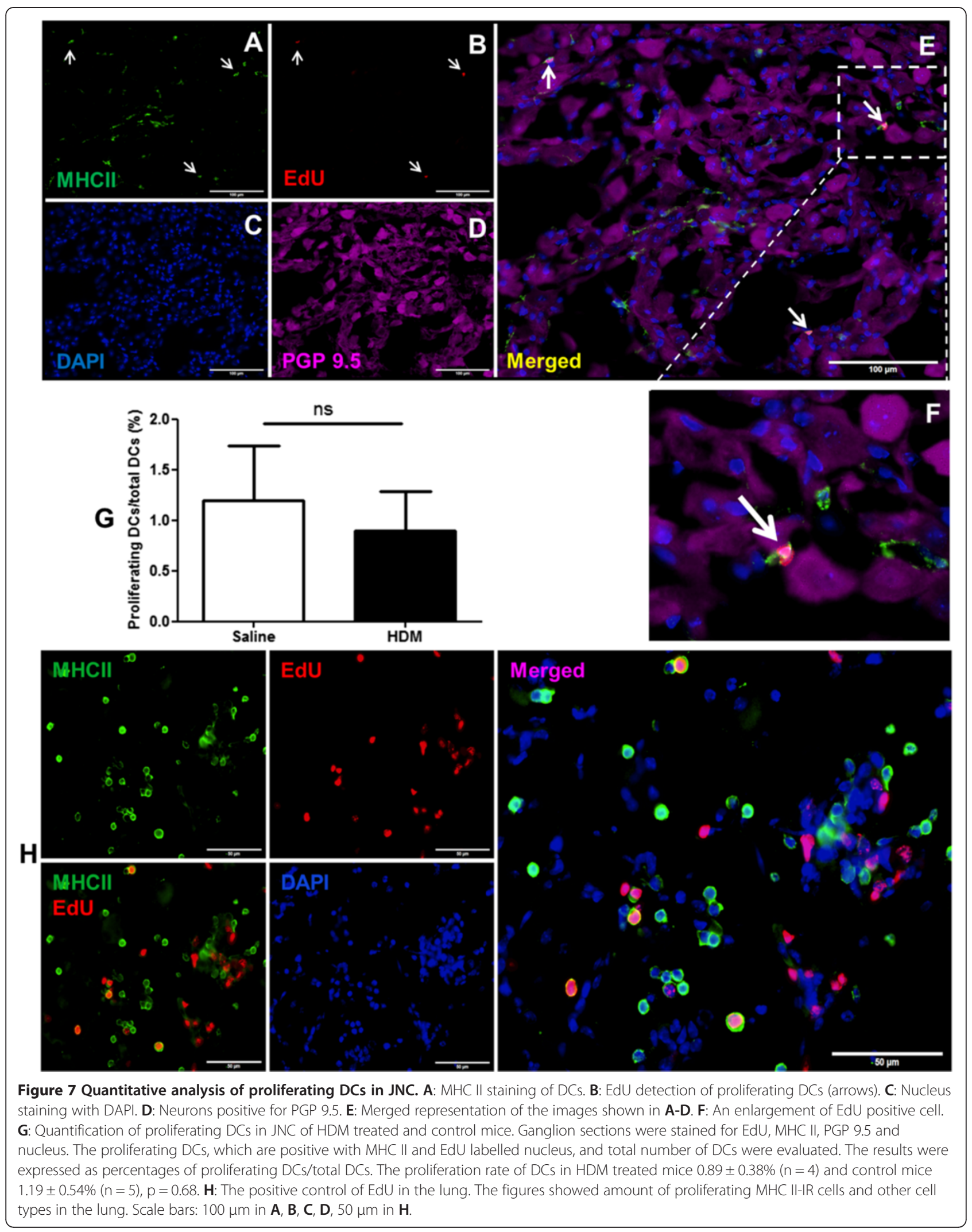


airway inflammation $[34,35]$. The presence of DCs in JNC also may play a substantial role in the immune response to protect the neurons against viral and bacterial infection, virus replication and bacterial spread without any neuronal destruction [36-39]. In this respect, other immune cells like $\mathrm{T}$ cells and macrophages were recently found inside the HSV-1 latently infected trigeminal ganglia [36]. However, the origin and function of the DCs in JNC under normal and allergic airway conditions remains to be answered in future studies.

With respect to the neuroimmune interaction, maturation, migration and function of DCs during allergic airway inflammation have been reported to be modulated by neuropeptides like the calcitonin gene-related peptide (CGRP), tachykinins and vasoactive intestinal peptide (VIP) released from airway nerves fibers $[9,10,13,14]$. In view of modulatory effects of CGRP on DCs, sensory neurons in JNC were investigated for CGRP-expression. The significant increase of CGRP-IR-neurons and the elevated numbers of DCs in allergic airway response suggest that there may be a functional relationship between DCs and CGRP-IR-neurons.

The increased of CGRP-IR-neurons in HDM-treated mice may have an influence on the migration, proliferation or function of DCs in JNC. With respect to the effect of CGRP in allergic airway inflammation, a proinflammatory or antiinflammatory role of CGRP in allergic airway inflammation is therefore still controversially discussed $[9,10,12,40]$. The intragangionic release of CGRP within JNC has not been demonstrated so far in vivo. Previous study on rat has reported about the release of CGRP from isolated JNC after stimulation with different substances such as capsaicin, nitric oxide donor sodium nitroprusside [41]. Our findings showed an increase of CGRP-positive neurons in JNC, but a release of CGRP from the neuron into the ganglia could not be demonstrated in the present study. Based on this observation, we suggest that CGRP may be paracrinely released from the neurons or anterogradely transported to the peripheral nerve endings and liberated into the airways. The exact role of CGRP in sensory neurons concerning the modulation of DC-function during allergic airway response remains to be elucidated in future studies.

\section{Conclusion}

The present study revealed for the first time the existence of immune cells with DC phenotype within JNC. The increase of DCs and CGRP-positive neurons in airway ganglia caused by allergic airway inflammation indicates that ganglia DCs and neurons expressing CGRP may contribute to the pathogenesis of bronchial asthma. These findings demonstrate that DCs may migrate from outside into the ganglia to interact with sensory neurons enhancing or protecting the allergic airway inflammation.
Further studies should be carried out to explore the interaction of DCs and neurons in airway sensory ganglia during allergic airway inflammation.

\section{Abbreviations}

APC: Antigen-presenting cell; APES: 3-Aminopropyltriethoxysilane; BALF: Bronchoalveolar lavage fluid; CGRP: Calcitonin gene-related peptide; DC: Dendritic cells; DAPI: 4', 6-diamidino-2-phenylindol dihydrochloride; EdU: 5-ethynyl-2'-deoxyuridine; GFAP: Glial fibrillary acidic protein; GS: Glutamine synthetase; HDM: House dust mite; H\&E: Hematoxylin and eosin; Iba1: Ionized calcium binding adapter molecule 1; IR: Immunoreactive; JNC: Jugular-nodose ganglia complex; LPS: Lipopolysaccharide; MHC II: Major histocompatibility class II; PAS: Periodic Acid Schiff; PBS: Phosphate buffered saline; PGP 9.5: Protein gene product 9.5; SGC: Satellite glia cell; VIP: Vasoactive intestinal peptide.

\section{Competing interests}

None of the authors have a financial relationship with a commercial entity that has an interest in the subject of this manuscript.

\section{Authors' contributions}

The authors AF, TT, RB, TW, AB, MS QTD designed the study. DDL, SR, SH performed animal experiments and analysed the data. DDL, QTD wrote the manuscript. All authors read and approved the manuscript.

\section{Acknowledgments}

This project was supported by GRK 1441 "Regulation of the Allergic Inflammatory Response in Lung and Skin" to Prof. T. Welte and Prof. Q.T. Dinh, by the German Research Foundation (DFG, DI 1429/2-1) and by the foundation "Stiftung Bergmannshilfswerks Luisenthal" to Prof. Q.T. Dinh, by SFB587 B4 and by IMI UBIOPRED to Prof. A. Braun.

\section{Author details}

'Department of Experimental Pneumology and Allergology, Saarland University Faculty of Medicine, Kirrberger Strasse, Geb. 61.4, Homburg, Germany. ${ }^{2}$ Department of Airway Immunology, Fraunhofer Institute for Toxicology and Experimental Medicine, German Centre for Lung Research (DZL), Hannover, Germany. Institute of Occupational Medicine, Charité Universitätsmedizin Berlin, Free University and Humboldt University, Berlin, Germany. Institute of Anatomy and Cell Biology, Saarland University Faculty of Medicine, Homburg, Germany. ${ }^{5}$ Department of Transplant and Infection Immunology, Saarland University, Homburg, Germany. ${ }^{6}$ Department of Internal Medicine V, Pneumology, Allergology and Respiratory Critical Care Medicine, Saarland University Faculty of Medicine, Kirrberger Strasse, Geb. 61.4, Homburg, Germany. ${ }^{7}$ Department of Pneumology, Hannover Medical School, German Centre for Lung Research (DZL), Hannover, Germany.

Received: 21 January 2014 Accepted: 23 June 2014

Published: 30 June 2014

\section{References}

1. Barnes PJ: Pathophysiology of allergic inflammation. Immunol Rev 2011, 242:31-50.

2. Gill MA: The role of dendritic cells in asthma. J Allergy Clin Immunol 2012, 129:889-901.

3. Lambrecht BN: Dendritic cells and the regulation of the allergic immune response. Allergy 2005, 60:271-282.

4. Novak N, Haberstok J, Geiger E, Bieber T: Dendritic cells in allergy. Allergy 1999, 54:792-803.

5. Bulloch K, Miller MM, Gal-Toth J, Milner TA, Gottfried-Blackmore A, Waters EM, Kaunzner UW, Liu K, Lindquist R, Nussenzweig MC, Steinman RM, McEwen BS: CD11c/EYFP transgene illuminates a discrete network of dendritic cells within the embryonic, neonatal, adult, and injured mouse brain. J Comp Neurol 2008, 508:687-710.

6. Steinman RM, Banchereau J: Taking dendritic cells into medicine. Nature 2007, 449:419-426.

7. Vermaelen KY, Carro-Muino I, Lambrecht BN, Pauwels RA: Specific migratory dendritic cells rapidly transport antigen from the airways to the thoracic lymph nodes. J Exp Med 2001, 193:51-60. 
8. Lambrecht BN, Hammad $\mathrm{H}$ : The role of dendritic and epithelial cells as master regulators of allergic airway inflammation. Lancet 2010, 376:835-843.

9. Dunzendorfer S, Kaser A, Meierhofer C, Tilg H, Wiedermann CJ: Cutting edge: peripheral neuropeptides attract immature and arrest mature blood-derived dendritic cells. J Immunol 2001, 166:2167-2172.

10. Rochlitzer S, Veres TZ, Kuhne K, Prenzler F, Pilzner C, Knothe S, Winkler C, Lauenstein HD, Willart M, Hammad H, Müller M, Krug N, Lambrecht BN, Braun A: The neuropeptide calcitonin gene-related peptide affects allergic airway inflammation by modulating dendritic cell function. Clin Exp Allergy 2011, 41:1609-1621.

11. Joos GF, Germonpre PR, Pauwels RA: Role of tachykinins in asthma. Allergy 2000, 55:321-337.

12. Groneberg DA, Quarcoo D, Frossard N, Fischer A: Neurogenic mechanisms in bronchial inflammatory diseases. Allergy 2004, 59:1139-1152.

13. Dinh QT, Mingomataj E, Quarcoo D, Groneberg DA, Witt C, Klapp BF, Braun A, Fischer A: Allergic airway inflammation induces tachykinin peptides expression in vagal sensory neurons innervating mouse airways. Clin Exp Allergy 2005, 35:820-825.

14. Fischer A, McGregor GP, Saria A, Philippin B, Kummer W: Induction of tachykinin gene and peptide expression in guinea pig nodose primary afferent neurons by allergic airway inflammation. J Clin Invest 1996, 98:2284-2291.

15. Barnes PJ: Neurogenic inflammation in the airways. Respir Physiol 2001, 125:145-154.

16. Davies D, Medeiros MS, Keen J, Turner AJ, Haynes LW: Eosinophil chemotactic peptide sequences in rat alpha-CGRP. Activation of a novel trophic action by neutral endopeptidase 24.11. Ann N Y Acad Sci 1992, 657:405-411.

17. Foster CA, Mandak B, Kromer E, Rot A: Calcitonin gene-related peptide is chemotactic for human T lymphocytes. Ann N Y Acad Sci 1992, 657:397-404.

18. Lambrecht BN: Immunologists getting nervous: neuropeptides, dendritic cells and T cell activation. Respir Res 2001, 2:133-138.

19. Kawanami Y, Morimoto Y, Kim H, Nakamura T, Machida K, Kido T, Asonuma E, Yatera K, Yoshii C, Kido M: Calcitonin gene-related peptide stimulates proliferation of alveolar epithelial cells. Respir Res 2009, 10:8

20. Braun A, Lommatzsch M, Mannsfeldt A, Neuhaus-Steinmetz U, Fischer A, Schnoy N, Lewin GR, Renz H: Cellular sources of enhanced brain-derived neurotrophic factor production in a mouse model of allergic inflammation. Am J Respir Cell Mol Biol 1999, 21:537-546.

21. Noga O, Peiser M, Altenahr M, Schmeck B, Wanner R, Dinh QT, Hanf G, Suttorp N: Selective induction of nerve growth factor and brain-derived neurotrophic factor by LPS and allergen in dendritic cells. Clin Exp Allergy 2008, 38:473-479.

22. Veres TZ, Rochlitzer S, Shevchenko M, Fuchs B, Prenzler F, Nassenstein C, Fischer A, Welker L, Holz O, Muller M, Krug N, Braun A: Spatial interactions between dendritic cells and sensory nerves in allergic airway inflammation. Am J Respir Cell Mol Biol 2007, 37:553-561.

23. Hosoi J, Murphy GF, Egan CL, Lerner EA, Grabbe S, Asahina A, Granstein RD: Regulation of Langerhans cell function by nerves containing calcitonin gene-related peptide. Nature 1993, 363:159-163.

24. Groth M, Helbig T, Grau V, Kummer W, Haberberger RV: Spinal afferent neurons projecting to the rat lung and pleura express acid sensitive channels. Respir Res 2006, 7:96

25. Dinh QT, Groneberg DA, Peiser C, Joachim RA, Frossard N, Arck PC, Klapp BF, Fischer A: Expression of substance $P$ and nitric oxide synthase in vagal sensory neurons innervating the mouse airways. Regul Pept 2005, 126:189-194.

26. Dinh QT, Groneberg DA, Peiser C, Springer J, Joachim RA, Arck PC, Klapp BF, Fischer A: Nerve growth factor-induced substance $P$ in capsaicin-insensitive vagal neurons innervating the lower mouse airway. Clin Exp Allergy 2004, 34:1474-1479.

27. Johnson JR, Wiley RE, Fattouh R, Swirski FK, Gajewska BU, Coyle AJ, Gutierrez-Ramos JC, Ellis R, Inman MD, Jordana M: Continuous exposure to house dust mite elicits chronic airway inflammation and structural remodeling. Am J Respir Crit Care Med 2004, 169:378-385.

28. Tomlinson KL, Davies GC, Sutton DJ, Palframan RT: Neutralisation of interleukin-13 in mice prevents airway pathology caused by chronic exposure to house dust mite. PLoS One 2010, 5(10):e13136. doi:10.1371/ journal.pone.0013136.
29. van Velzen $M$, Laman JD, Kleinjan A, Poot A, Osterhaus AD, Verjans GM: Neuron-interacting satellite glial cells in human trigeminal ganglia have an APC phenotype. J Immunol 2009, 183:2456-2461.

30. Chen ZW, Ahren B, Ostenson CG, Cintra A, Bergman T, Moller C, Fuxe K, Mutt $V$, Jornvall $H$, Efendic S: Identification, isolation, and characterization of daintain (allograft inflammatory factor 1), a macrophage polypeptide with effects on insulin secretion and abundantly present in the pancreas of prediabetic BB rats. Proc Natl Acad Sci U S A 1997, 94:13879-13884.

31. Orsmark C, Skoog T, Jeskanen L, Kere J, Saarialho-Kere U: Expression of allograft inflammatory factor-1 in inflammatory skin disorders. Acta Derm Venereol 2007, 87:223-227.

32. Hanani M: Satellite glial cells: more than just 'rings around the neuron'. Neuron Glia Biol 2010, 6:1-2.

33. Ten Tusscher MP, Klooster J, Vrensen GF: Satellite cells as blood-ganglion cell barrier in autonomic ganglia. Brain Res 1989, 490:95-102.

34. Veres TZ, Voedisch S, Spies E, Valtonen J, Prenzler F, Braun A: Aeroallergen challenge promotes dendritic cell proliferation in the airways. J Immunol 2013, 190:897-903.

35. van Rijt LS, Prins JB, Leenen PJ, Thielemans K, de Vries VC, Hoogsteden HC, Lambrecht BN: Allergen-induced accumulation of airway dendritic cells is supported by an increase in CD31(hi)Ly-6C(neg) bone marrow precursors in a mouse model of asthma. Blood 2002, 100:3663-3671.

36. Theil D, Derfuss T, Paripovic I, Herberger S, Meinl E, Schueler O, Strupp M, Arbusow $V$, Brandt $T$ : Latent herpesvirus infection in human trigeminal ganglia causes chronic immune response. Am J Pathol 2003, 163:2179-2184.

37. Tsiang $H_{1}$ Ceccaldi PE, Lycke E: Rabies virus infection and transport in human sensory dorsal root ganglia neurons. J Gen Virol 1991, 72(Pt 5):1191-1194.

38. Li XQ, Fu ZF, Alvarez R, Henderson C, Tripp RA: Respiratory syncytial virus (RSV) infects neuronal cells and processes that innervate the lung by a process involving RSV G protein. J Virol 2006, 80:537-540.

39. Antinone SE, Smith GA: Retrograde axon transport of herpes simplex virus and pseudorabies virus: a live-cell comparative analysis. J Virol 2010, 84:1504-1512.

40. Voedisch S, Rochlitzer S, Veres TZ, Spies E, Braun A: Neuropeptides contro the dynamic behavior of airway mucosal dendritic cells. PLoS One 2012, 7:e45951.

41. Strecker T, Koulchitsky S, Dieterle A, Neuhuber WL, Weyand M, Messlinger K: Release of calcitonin gene-related peptide from the jugular-nodose ganglion complex in rats-a new model to examine the role of cardiac peptidergic and nitrergic innervation. Neuropeptides 2008, 42:543-550.

doi:10.1186/1465-9921-15-73

Cite this article as: Le et al:: Allergic airway inflammation induces the migration of dendritic cells into airway sensory ganglia. Respiratory Research 2014 15:73.

\section{Submit your next manuscript to BioMed Central and take full advantage of:}

- Convenient online submission

- Thorough peer review

- No space constraints or color figure charges

- Immediate publication on acceptance

- Inclusion in PubMed, CAS, Scopus and Google Scholar

- Research which is freely available for redistribution 